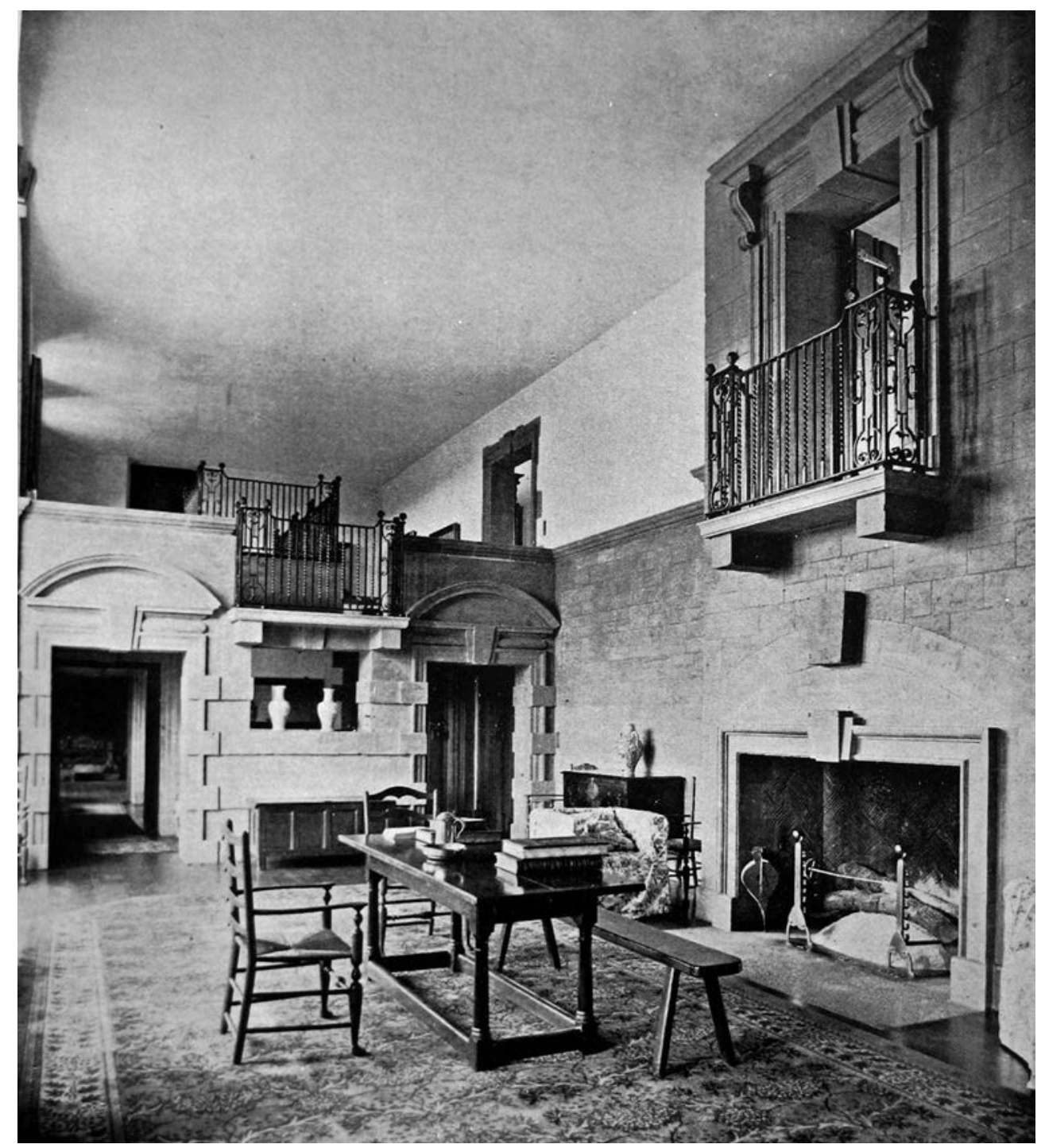

\title{
Reflexiones sobre un balcón: Lutyens y la técnica de montaje_
}

Manuel de Prada Pérez de Azpeitia*

Resumen / Abstract pág 48| Bibliografía pág 52

Edwin Landseer Lutyens (1869-1944) fue considerado por sus contemporáneos el último arquitecto romántico de Inglaterra. La ironía y el ingenio fueron los aspectos más destacados de su carácter. Sir Albert Richardson, con motivo del fallecimiento del arquitecto, escribió: "como romántico, se sitúa entre los más grandes, acaso, como descendiente de Wren. Su carrera interesará como la de un empedernido humorista, su arte se medirá en la balanza romántica".1 La misión de Lutyens, según Richardson, fue crear edificios con encanto. Pero ni el encanto ni la romántica ironía eran del agrado de aquellos que, desde posiciones moralistas heredadas de Pugin y Morris, defendían una arquitectura medieval idealizada, supuestamente libre y funcional. Los ideólogos de la arquitectura funcional, entre los que destacan Muthesius y Pevsner, no entendieron que arquitectos tan capaces como Richard Norman Shaw y Edwin Lutyens aceptaran el "frío abrazo del clasicismo". Pevsner reconocía las cualidades espaciales de los edificios de Lutyens. Respecto a Little Thakeham escribió: "el manejo del espacio por parte de Lutyens no ha sido suficientemente apreciado en el pasado. La escalera de Little Thakeham es casi tan ingeniosa por su geometría como las escaleras del siglo XVII que admiramos en Alemania y en Austria".2 Pero inmediatamente exponía la irritación que le causaban los detalles clasicistas y los juegos formales a los que solía recurrir el arquitecto.

Mientras Frank Lloyd Wright se declaraba admirador de Lutyens y su obra ${ }^{3}$, Pevsner se preguntaba por qué Lutyens era tan admirado en Inglaterra. La respuesta, pensaba, está relacionada con el gusto de los ingleses por la excentricidad. El título del artículo que dedicó al arquitecto, "Construyendo con ingenio", daba a entender que Lutyens construía solo con ingenio. ${ }^{4}$ Años después, un seguidor de Pevsner, Robert Furneaux Jordan, calificó a Lutyens de "magnífico pasticheur": "esas famosas casas de ensueño... quedarán como un monumento curioso, no a la cultura -porque se encuentran totalmente fuera de su tiempo- sino a un hombre. Al igual que un sueño son irreales, y al igual que un sueño no han dejado nada tras ellas", escribió Jordan. ${ }^{5}$ Poco después, Alison y Peter Smithson acusaron a Lutyens de poner la degradación del lenguaje de la arquitectura en las manos de todo el mundo. ${ }^{6,7}$ Pero algo estaba cambiado. Robert Venturi había publicado su libro Complexity and Contradiction in Architecture (1966) y había ilustrado
Palabras clave

Lutyens

Little Thakeham

hall

screen

Prentice

montaje

Le Corbusier

De Besistegui

[1] Edwin Lutyens, Salón de Little Thakeham 1902-1903. Vista del salón hacia el screen. Country Life Picture Library. Image Number: 840323 . www.countrylifeimages.co.uk También reproducida en el libro de Lawrence Weaver, Houses and Gardens by E. L. Lutyens, 1913, pág 105 de la edición Antique Collectors' Club, 1981 
1 The Builder, vol. XIX, 1944, pág 32. También citado por Gavin Stamp en el artículo "The Rise and Fall and Rise of Edwin Lutyens", Architectural Review, Noviembre, 1981. Publicado además en la revista Quaderns d'arquitectura i Urbanisme, $\mathrm{n}^{\circ}$ $155,1982$.

2 Pevsner, Nicolaus; "Building With Wit. The Architecture of Sir Edwin Lutyens", Architectural Review, Abril, 1951. También reproducido en Service, Alastair; Edwardian Architecture and its Origins, Architectural Press, 1975, págs 460-470.

3 Pensando en las primeras casas construidas por Lutyens, Frank Lloyd Wright escribió: "Para él, la chimenea inglesa, el gablete, el pilar monumentalizado gracias a una buena obra de ladrillo y mampostería eran motivos que debían ser dramatizados con gran habilidad". Wright, $F$. L.; "Sir Edwyn Lutyens", Review of The Memorial Volumes, Building, Julio, 1951, págs 260-62. De Gavin Stamp; "Lutyens, Sir Edwin Landseer (1869-1944)", Oxford Dictionary of National Biography, Oxford University Press, 2004; online edn, May 2012. (http://www.oxforddnb.com/view/ article/34638, accessed 24 Oct 2013). Allan Greenberg ha comparado algunas plantas de Lutyens con otras de su contemporáneo Frank Lloyd Wright. Ninguno influyó en el otro, sostiene Geenberg, pero Wright admiraba a Lutyens, "porque en él vio una gran mente luchando con problemas similares y recurriendo a principios de organización semejantes". Greenberg, Allan; Lutyens and the Modern Movement, Papadakis Publishing, 2007, pág 147

${ }^{4}$ Pevsner, Nicolaus; "Building With Wit. The Architecture of Sir Edwin Lutyens", Architectural Review, Abril, 1951.

5 Jordan Robert F.; Victorian Architecture, Tenguin Books, Harmonds worth, 1966.

${ }^{6}$ Smithson, Alison and Peter; "The responsability of Lutyens", RIBA Journal, vol 76, Abril, 1969.

7 Todo ello lo desarrolla Gavin Stamp en el artículo significativamente titulado "La ascensión, caída y ascensión de Edwin Lutyens": "The Rise and Fall and Rise of Edwin Lutyens", Architectural Review, Noviembre, 1981, págs 311-318.

${ }^{8}$ Venturi, Robert; Complejidad y contradicción en la arquitectura, fig. 56, pág 59, Gustavo Gili, Barcelona, 1972.

${ }^{9}$ Venturi, Robert, Scott Brown, Denise; "Learning from Lutyens", RIBA Journal, vol 76, pág 353, Agosto, 1969.

10 Greenberg, Allan; "Lutyens's architecture restudied" Perspecta, volume XII, pág 129-152, 1969.

11 Greenberg, Allan; Lutyens and the Modern Movement, Papadakis Publisher, Winterbourne, 2007.

12 Existen numerosos estudios sobre el montaje cinematográfico, pero no asi sobre la poética del montaje referida al resto de las artes. El libro titulado Arte, arquitectura y montaje, escrito por el autor de este ensayo, se encuentra en proceso de publicación. Uno de los estudios pioneros sobre los fundamentos del cine y del montaje cinematográfico es et de Hugo Mustemberg, Photoplay. A psycological study. (Appleton, New York \& London, 1916). Eisenstein, en cualquier caso, definió claramente el montaje: una idea que surge de la colisión de dos piezas, independientes la una de la otra. Según Eisenstein, el montaje parte de elementos, imágenes o escenas concretas para llegar a conceptos e ideas de compleja representación. Véase: Eisenstein, Serguéi; El sentido del cine, Siglo XXI, México D. F. 1986. También puede verse: Eisenstein, $S$. Hacia una teoría del montaje, Vol. I y II. Paidós, Barcelona, 2001. Recientemente Georges DidiHuberman, remitiéndose a Eisenstein, Kulechov, Brecht y los formalistas rusos, a los PassagenWerk de Benjamin y al Atlas Mnemosine de Warburg, postuló un modo de conocimiento aplicable tanto a la historia como al arte, que denominó "conocimiento por el montaje". Entrevista con Pedro G. Romero. 2007. http:// www.revistaminerva.com/articulo.php?id=141 (10-25-2013). alguna de sus tesis con obras de Lutyens: la fachada de Grey Walls, por ejemplo, con las dos chimeneas que enmarcan la entrada, le sirvió para ilustrar el empleo de elementos con doble función: utilitaria y representativa. ${ }^{8}$

A finales de la década de los 60 , las complejidades y contradicciones presentes en la obra de Lutyens comenzaron a ser de nuevo apreciadas. Venturi y Scott Brown denunciaron la inconsistencia de los ataques de los Smithsons y relacionaron sus argumentos con la infantil necesidad de interpretar la arquitectura en términos de "buenos contra malos". En el artículo titulado Learning from Lutyens, escribieron: "...el aspecto más perturbador para nosotros (de los artículos de los Smithsons contra Lutyens) es la posición vacía-heroica del arquitecto salvado... que está seguro de las respuestas". ${ }^{9}$ El mismo año Allan Greenberg, fascinado por las paradojas y ambigüedades presentes en la obra de Lutyens, relacionó a este arquitecto con Frank Lloyd Wright y Le Corbusier. ${ }^{10}$

Desde los años 70 el prestigio de Lutyens ha ido en aumento. En un libro de reciente publicación, Lutyens and the Modern Movement ${ }^{11}$, Greenberg insiste la admiración que Frank Lloyd Wright y Le Corbusier sintieron por Lutyens. No obstante, existen aspectos de la obra de Lutyens que todavía no han sido suficientemente explicados. En particular, el recurso a la yuxtaposición de elementos como parte de una estrategia destinada a renovar las formas tradicionales.

Para aclarar el valor poético de dicha estrategia se recurrirá aquí a un solo ejemplo: el balcón de reja que Lutyens abrió hacia el salón de Little Thakeham y que situó sobre la chimenea.

\section{El balcón interior de Little Thakeham}

El segundo año del siglo XX Edwin Lutyens diseñó Little Thakeham, una casa de campo que destaca por los detalles clasicistas y por los balcones de reja que se abren hacia el salón. Uno de estos balcones, el que se encuentra sobre la chimenea, será el objeto de las siguientes reflexiones.

Se trata de un balcón singular por varias razones. Porque se abre hacia un espacio interior y no hacia el exterior, como suelen hacer los balcones. Porque tiene un antepecho de reja metálica, algo extraño en Inglaterra. Por su posición, situado en el eje transversal del salón pero desplazado del eje de la residencia. Y por encontrarse encima de una chimenea, lo cual obliga a situar la salida de humos a un lado y produce la inquietante sensación de que el humo escapará a través del balcón cuando la chimenea esté encendida. [1] Singularidades que se van a explicar atendiendo a la poética del montaje, la cual persigue hacer presente la conexión, no en el nivel de las apariencias, sino en el de los significados; al modo de representar que tiene como fin provocar, mediante la yuxtaposición de elementos diferentes, la chispa del encuentro poético. ${ }^{12}$

Es suficiente un rápido repaso a la obra del arquitecto para comprobar su gusto por la yuxtaposición de elementos contrastantes, incluso discordantes, como el balcón interior y la chimenea. Los balcones abiertos hacia el interior se encuentran en muchas obras de Lutyens. Nada más atravesar el portalón de la sede de la revista Country Life, por ejemplo, encontramos el balcón que remata la escalera. Su antepecho no es de reja metálica, como tampoco los antepechos de los balcones que dan al salón de Folly Farm. Pero otros balcones interiores proyectados por Lutyens tienen antepechos de reja metálica: el que se abre hacia el salóndescansillo de Nashdom, por ejemplo, o los que acompañan en el salón al balcón objeto de este estudio, ambos situados en el eje longitudinal del espacio y ajustados en sus dimensiones a la estructura de la escalera: el primero entre los accesos del screen, y el segundo, detrás, ligeramente elevado. [2]

La escalera de Little Thakeham tiene suficiente relevancia para merecer un estudio independiente. Su valor arquitectónico ha sido sobradamente reconocido. Pero un balcón de reja abierto hacia el salón de una casa inglesa, situado además sobre una chimenea, no se puede justificar fácilmente. Es algo extraño, tanto desde el punto de vista de la función como de la representación.

Ciertamente Lutyens disfrutaba yuxtaponiendo elementos de distintos estilos y procedencias. Sus residencias son cajas de sorpresas. Pero si el arquitecto solo pretendiera provocar o sorprender, podría haber recurrido a formas más exóticas y extravagantes. Una rápida mirada a la residencia es suficiente para comprobar que el juego de Lutyens no es el de las formas extravagantes o exóticas, sino el de los contrastes significativos. El contraste entre el desnudo exterior de Little Thakeham, de aspecto vagamente medieval [3], y el ornamentado

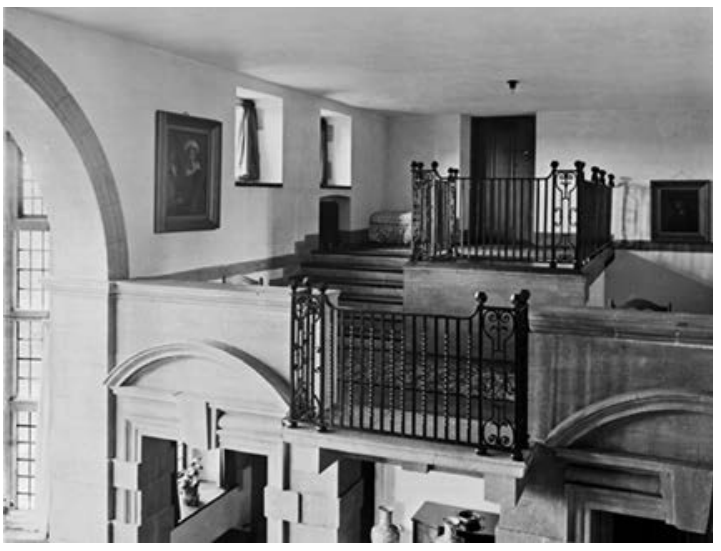

[2] Edwin Lutyens. Hall de Little Thakeham. 1902 1903. Vista de la parte superior del screen y de la balconada que remata la escalera. Country Life Picture Library. Image Number: 841106 http://www.countrylifeimages.co.uk También reproducida en el libro de Lawrence Weaver, Houses and Gardens by E. L. Lutyens. 1913, pág 104 de la edición Antique Collectors' Club, 1981. 
13 Stamp, Gavin / Richardson, Margaret; "Lutyens and Spain", Revista Quaderns d'arquitectura i Urbanisme, n 155, 1982, págs 58-81. Este artículo también fue publicado, un año después, por la revista Annals of the Architectural Association School of Architecture. (A.A. Files, 1983).

14 Prentice, Andrew Noble; Renaissance Architecture and Ornament in Spain: a series of examples selected from the purest Works executed between the years 1500-1560 B. ol año 1970 po Alec Tiranti con una introducción de Harold W. Bootom y nuevas ilustraciones.

15 "En Arquitectura Palladio es el juego. Es algo grande. Pocos lo aprecian hoy porque valora y manejar este juego requiere un considerable entrenamiento. Wren lo hizo de forma maravillosa. Shaw también tení ese talento. Para el hombre de la calle no es más que algo estéril pero en la mente de un Wren, brilla de tal manera, que el duro material se transforma en algo plástico como la arcilla... Es un juego que nunca decepciona. constante esfuerzo intelectual. Si este esfuerzo es muy laborioso, el juego falla. No se puede confiar en la suerte como ayuda y su complicada maquinaria hace que parezca imposible si no es en las manos de Jones o Wren. Así que es un gran juego, un elevado juego." Edwin Lutyens; Carta escrita el año 1903 a su amigo Herbert Baker y publicada por Butler, A.S.G. en The Domestic Architecture of Sir Edwin Lutyens, Country Life, London, 1950. Otros fragmentos de la misma carta se encuentran traducidos al español en el libro de John Summerson; El lenguaje clásico de la arquitectura, Gustavo Gili, Barcelona, 1974 (1963), págs 34-35.

${ }^{16}$ Benjamin, Walter; El concepto de crítica de arte en el Romanticismo alemán, Península, Barcelona, 1995. (Titulo original Der Begriff der Kunstkritik in der deutschen Romantik, Primera impresión de 1920.)

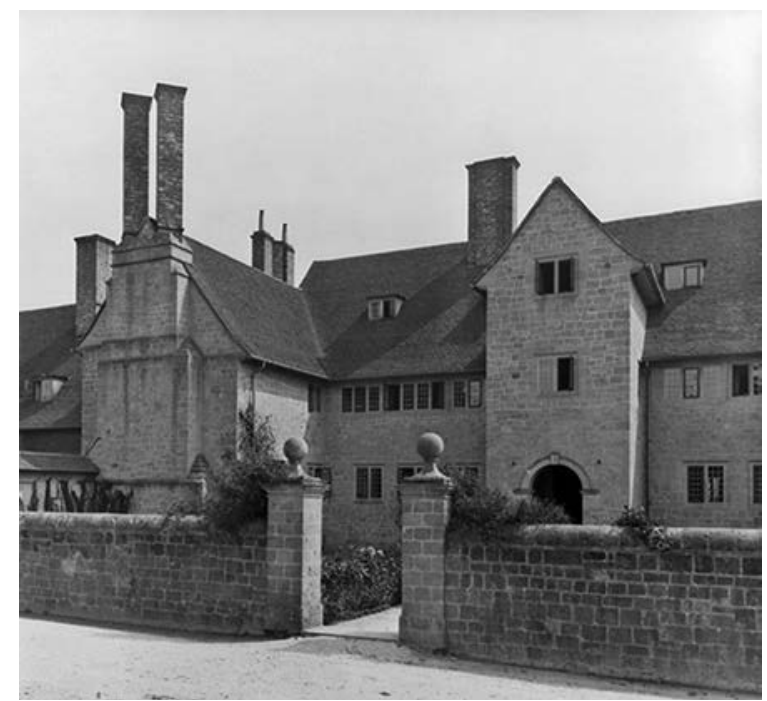

[3] Edwin Lutyens. Fachada principal de Little Thakeham. 1903. Country Life Picture Library. Image Number: 840562 http://www.countrylifeimages.co.uk También reproducida en el libro de Lawrence Weaver; Houses and Gardens by E. L. Lutyens, 1913, Edición Antique Collectors' Club, 1981.

interior, de aspecto vagamente mediterráneo, no es un capricho. El balcón interior interviene en este juego de contrastes y propone el vuelo de la imaginación hacia un reino donde los opuestos no son excluyentes y lo propio se entiende por relación a lo ajeno. Comparte aspecto y protagonismo con los detalles clasicistas y colabora con ellos en la definición de un espacio de carácter ambiguo, interior y exterior a la vez, inglés y mediterráneo.

Los detalles clasicistas y la reja sitúan este balcón a medio camino entre los balcones del Renacimiento Italiano y los balcones que caracterizan la arquitectura Plateresca. Y sin duda tiene un carácter español, aunque mire hacia el interior. Nos acercamos pues a la arquitectura española para verificar si en ella tiene su origen.

Es conocido que Lutyens realizó varios viajes a España. Están bien documentados en el artículo de Gavin Stamp y Margaret Richardson titulado "Lutyens and Spain".13 En la primera carta enviada a su esposa desde España, insiste en la fuerte impresión que le causaron los altares, los retablos y las rejas del interior de las iglesias. Pero esta carta fue escrita el año 1915, trece años después de haber proyectado Little Thakeham, lo cual implica que no conocía de primera mano la arquitectura española cuando proyectó esta residencia. La conocía, no obstante, a través de las ilustraciones de un libro.

Gavin Stamp y Margaret Richardson han señalado la gran acogida que recibió entre los arquitectos ingleses el libro de Andrew Noble Prentice Renaissance Architecture and Ornament in Spain, publicado el año $1893 .{ }^{14} \mathrm{El}$ libro presenta los dibujos que Prentice realizó en sus viajes por España, dibujos que muestran una arquitectura diferente a la inglesa pero atractiva para los arquitectos ingleses debido a su carácter pintoresco. De aquellos dibujos, según Stamp y Richardson, procede el interés de Lutyens por las rejas y por los balcones, por el contraste entre elementos ornamentados y paredes desnudas, y por los retablos, arquitecturas que miran hacia el interior pero que tienen cierto carácter de fachada exterior; arquitecturas comparables, desde este punto de vista, a los screens clasicistas de finales del siglo XVI y al screen de Little Thakeham, heredero directo de aquellos. $Y$ de aquellos dibujos Lutyens sacó buen provecho: cuatro años después de que el libro de Prentice se publicara y cinco años antes de proyectar Little Thakeham, diseño una hermosa divisoria de reja entre el altar y la nave de St. John Baptist Church, en Busbridge (Surrey), donde todavía se encuentra.

Pero ante todo Lutyens reconoció en los dibujos de Prentice una arquitectura que, al igual que la inglesa, había logrado conjugar dos tradiciones figurativas diferentes: la medieval y la clasicista. "Palladio es el juego", afirmaba el arquitecto, pero no el único juego. ${ }^{15}$ Lutyens disfrutaba jugando con el "lenguaje clásico de la arquitectura", pero también conjugando estructuras simétricas y asimétricas, formas clasicistas y medievales, motivos vernáculos y mediterráneos. Todos eran juegos al servicio de la memoria y la recreación de las formas. Tan admirables como los recursos compositivos de Wren, Hawksmoor, Archer, Vanbrugh o Nash eran para Lutyens los recursos y detalles de la arquitectura plateresca. Conjugarlos requería ingenio y romántica ironía, precisamente los rasgos que le caracterizaban.

En este punto conviene distinguir entre romántica ironía y arbitrario capricho. Y nada mejor, aún a riesgo de alejar estas reflexiones de su objeto, que recurrir a un pensador que dedicó al Romanticismo su obra primera. La romántica ironía ataca la forma sin destruirla, escribió Walter Benjamin. Muy lejos de representar una subjetiva veleidad del autor, disuelve la forma para hacer de la obra singular una obra de arte, para "romantizarla", pues procede del espíritu del arte y no de la voluntad del artista. "La ironía formal no es, como el esfuerzo o la sinceridad, un procedimiento intencional del autor. No puede ser entendida, según es costumbre, como índice de una subjetiva carencia de límites, sino que debe ser apreciada como un momento objetivo en la misma obra. Representa el intento paradójico de construir..., aun a través de una demolición".. ${ }^{16}$

Es necesario además aclarar que la ironía no es una característica exclusiva del Romanticismo. Los irónicos juegos del Barroco, por ejemplo, demostraron la validez de los principios del clasicismo. Comprometiendo la sintaxis clasicista, probaron su versatilidad, argumenta Manfredo Tafuri. Incluso cabría aplicar a Lutyens las palabras que el teórico italiano dedicó a Borromini: "el collage de elementos fuera de contexto que aparece en la obra de 
17 Tafuri, Manfredo; Teorías e Historia de la Arquitectura: hacia una nueva concepción del espacio arquitectónico, Laia, Barcelona, 1977. (Titulo original: Teorie e storia dell'architettura, Laterza, 1970). Tafuri afirma primero que Borromini anticipó una actitud típica de las vanguardias. Pero más adelante diferencia entre la actitud de las vanguardias, "siempre afirmativa, absolutista y totalitaria", que da por supuesto que su revolución lingüística realiza un cambio social moral, y la actitud experimentalista de Borromini, "cuya tarea real no es la de subvertir, sino la de dilatar, descomponer y recomponer en inéditas modulaciones el material lingüistico, los códigos figurativos y las convenciones que, por definición, asumen como realidad de fondo", págs 135-136 18 Los señores isabelinos deseaban demostra que conocian los avances en el diseño que procedian de Italia. Con este fin lograron concilia una envolvente exterior simétrica y regular, que representaba modernidad, con la distribución irregular y asimétrica, heredada de la antigua mansión medieval. Para ampliar la información puede verse Prada, Manuel; La casa inglesa. Función, forma y mito. Una revisión del modelo funcional, Nobuko, Buenos Aires, 2011.

19 Lloyd, Nathaniel; History of the English House, Architectural Press, London, 1975, pág 16. Atendiendo al significado de la palabra "nave", Nathaniel Lloyd ha sugerido que la estructura de madera del hall podria relacionarse con la forma (invertida) del casco de los barcos: "all the building illustrated thus far have more or less the form of inverted boats or ships... In this relation it is, therefore, interesting to note that the word nave is derived from the latin navis, while the german word for the nave of a church is schiff, a ship". Para Lloyd es significativo que la palabra alemana que designa la nave de una iglesia, schiff, sea muy parecida y tenga la misma pronunciación que la palabra inglesa ship, barco. También la palabra griega naós, santuario o capilla, está directamente emparentada con naus: nao, nave o navio. $Y$ todavía la palabra nave -del latín, navis- compart en español ambos significados: nave de iglesia y nave-embarcación

20 Véase Girouard, Mark; Life in the English Country House. A social and architectural history, Yale University Press, New Haven and London, 1984 (1978).
Borromini adquiere un nuevo sentido al subordinarse a una organización del espacio construida al margen de él". ${ }^{17}$ Comparación poco ortodoxa, pero pertinente, si atendemos al papel que desempeña el balcón de Little Thakeham en la organización de unos espacios construidos al margen de él.

\section{La organización espacial de Little Thakeham}

Cuando Lutyens conjuga la simetría exterior con una distribución asimétrica no inventa nada. Recrea lo que se había hecho en Inglaterra en la segunda mitad del siglo XVI.

La misión del balcón y la chimenea es señalar el eje transversal del hall. Pero este eje no coincide con el eje exterior de la casa, materializado por el porche de acceso y por el ventanal poligonal que mira hacia el jardín. No le habría costado mucho a Lutyens desplazar el hall hacia la derecha para que la chimenea y el balcón coincidieran con el eje exterior de la casa. Tampoco sustituir la chimenea (que como consecuencia de este desplazamiento quedaría frente al porche de acceso) por una puerta que permitiera el acceso directo al salón y reafirmara en el interior el eje de la residencia. Todo quedaría bien encajado. Pero entonces se perderían la privacidad y el tradicional acceso al hall por uno de sus extremos, a través del screen.

Tal y como se aprecia en la planta baja, para llegar al salón es necesario atravesar el porche de acceso, girar $90^{\circ}$ en el corredor hacia la derecha, girar hacia la izquierda y entrar en el screen passage desde el que arranca la escalera, para finalmente volver a girar $90^{\circ}$ hacia la izquierda y acceder por cualquiera de las dos puertas del screen. Este recorrido recrea el tradicional acceso al banqueting hall desde el exterior de la residencia, siempre realizado a través del screen passage mediante un giro de $90^{\circ}$. De modo que en el salón de Little Thakeham se encuentran tres ejes. Dos de ellos son paralelos: el eje transversal del espacio (señalado por la chimenea y el balcón) y el eje exterior del edificio (señalado por el ventanal poligonal hacia el jardín). El tercero es el eje longitudinal del salón, que se cruza con los dos anteriores y se manifiesta en la simetría del screen: en los dos accesos al salón, en el hueco entre ellos y en los dos balcones de reja escalonados.

Little Thakeham continúa las experiencias de Tigbourne Court (1899) y de Marshcourt (1901). Pero además recrea la ordenación de una singular residencia isabelina, Wollaton Hall. Las diferencias entre Wollaton Hall y Little Thakeham son evidentes. La escalera de Wollaton está situada a la izquierda del acceso y es independiente del hall. Tendríamos que trasladar mentalmente esta escalera detrás del screen passage para obtener una distribución semejante. Pero existen analogías muy significativas. El screen de Wollaton, al igual que el de Little Thakeham, es de piedra y está decorado a la italiana, como si fuera una fachada exterior. En ambas residencias el eje de acceso se interrumpe bruscamente, de manera que hay que realizar varios giros de 90 grados para acceder al hall por uno de sus lados. Y en ambas el salón mantiene las características generales del antiguo banqueting hall: un espacio direccional de gran altura con una balconada abierta hacia él. ${ }^{18}$

El banqueting hall medieval era la pieza central de un conjunto asimétrico en forma de " $\mathrm{H}$ ". La cubierta tenía dos aguas y estaba sostenida por grandes cerchas de madera semejantes a las de los graneros. No era un espacio funcional, sino representativo. Su gran altura y tamaño lo hacían poco confortable. Estaba atravesado por frías corrientes de aire y permanecía vacío la mayor parte del tiempo, pues solo se utilizaba para las grandes celebraciones. Además se debía atravesar en toda su longitud para llegar hasta las habitaciones del señor.

A principios del siglo XIV los muros del hall se construyeron de piedra y se abrieron en ellos grandes ventanales apuntados, por lo cual el este espacio comenzó a parecerse a la nave de una iglesia. ${ }^{19}$ [4] La mesa del señor, situada sobre el dais (una tarima ligeramente elevada al fondo del hal/), era compartida por su principal invitado y, en ocasiones, por el administrador de la casa. El resto de los invitados ocupaban dos largas mesas paralelas al eje, de manera que podían disfrutar de un doble espectáculo: hacia un lado, el espectáculo del señor y sus principales invitados sobre el dais, hacia el otro, el espectáculo del screen y la balconada de los músicos. En el momento en que la procesión de sirvientes atravesaba el screen y hacía su aparición en el hall portando las bandejas con la comida, los músicos, situados en la balconada situada sobre el screen passage, comenzaban a tocar. ${ }^{20}$

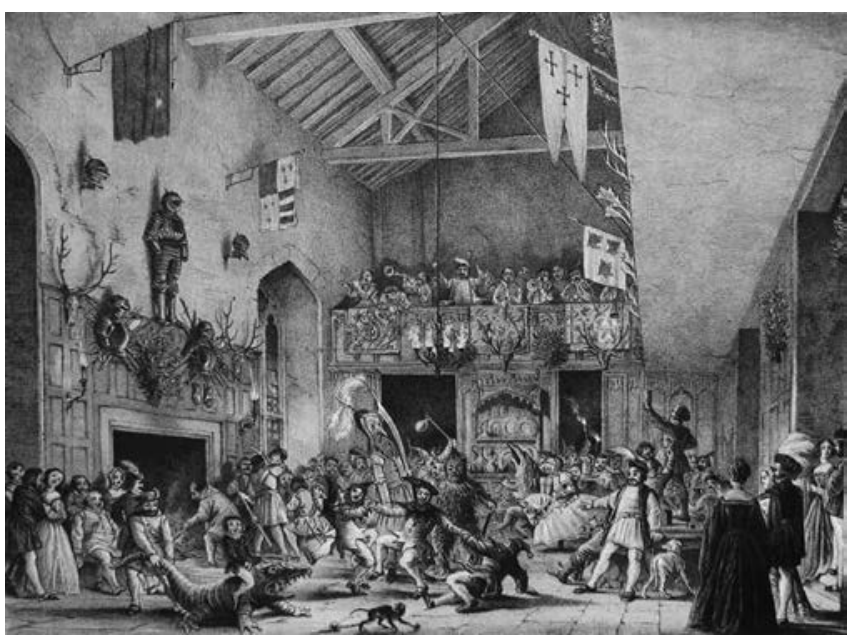


Desde una posición estrictamente funcionalista, solo hay algo tan inútil como un balcón abierto hacia un espacio interior: un banqueting hall tradicional. Cuando Muthesius se refiere al hall "de la antigüedad" lo hace para mostrar su falta de utilidad y para desaconsejar su empleo en la nueva arquitectura. Dice del hall lo siguiente: "...en esta forma se puede apreciar un fuerte contraste con el resto de las cualidades de la arquitectura inglesa moderna... El hall no tiene ninguna utilidad real. Existen pocas ocasiones para usar su gran capacidad. Se sitúa a un lado de la puerta principal, ocupando en la planta una posición equivocada"(sic). ${ }^{21}$

Pero el hall no era un espacio adecuado la función, sino al ritual. Durante las celebraciones, allí se confundían lo sagrado y lo profano. El señor de la casa representaba un papel semejante al del sacerdote en la iglesia. El dais hacía las veces del altar y el hall actuaba como si fuera la nave de una iglesia. [5] Y este aspecto de la imitación, en apariencia irrelevante, ofrece nuevas claves para entender el significado del balcón de Little Thakeham. Pues balcones semejantes, igualmente abiertos hacia un espacio interior, se encuentran en muchas iglesias barrocas, tanto españolas como iberoamericanas, en la iglesia del Monasterio de San Francisco de Jerez de la Frontera, por ejemplo, o en la iglesia del Rosario dos Homens Pretos, en Olinda, Brasil. [6, 7]

No se han encontrado evidencias de que Lutyens se haya fijado expresamente en este tipo de balcones. Pero la relación que aquí se propone no es contextual sino estructural. Se fundamenta en que todos estos balcones se abren hacia el interior, convierten el muro en una espacie de fachada y conceden al espacio un carácter ambiguo, interior y exterior a la vez. Lo cual permite sospechar que también Lutyens, en lugar de copiar, imitaba. Bien entendido que esta imitación nada tiene que ver con la copia. Que es la que tiene su origen en la "imitación diferida" del niño que juega a ser otro (incluso un avión o una locomotora, según un ejemplo de Benjamin), en la que Jean Piaget consideró fundamento de la función simbólica y, por tanto, de la inteligencia ${ }^{22}$ y en la que Henri Wallon implicó en el tránsito desde acto hacia pensamiento ${ }^{23}$. Esta es la mímesis que nos obliga a ponernos en la piel de otros para construir nuestra individualidad. En el campo del arte, la mímesis que Walter Benjamin relacionó con el surrealismo y el montaje de imágenes ${ }^{24}$ y la que Valeriano Bozal califica como "dinámica y creadora". 25

El balcón de reja convierte el salón de Little Thakeham en un actor capaz de representar al banqueting hall medieval haciendo como si fuera otro. El actor solo está en parte enmascarado. No hay trampa. Los detalles clasicistas que rematan el balcón tienen esa misma misión: recrear el hall medieval convirtiéndolo en otra cosa.

Además de la analogía entre balcones mencionada, existe un elemento proyectado por Le Corbusier comparable al balcón de Little Thakeham. Es la falsa chimenea barroca que el arquitecto francés empotró en el antepecho de la cubierta del apartamento que construyó en París para el excéntrico millonario Carlos de Beistegui. Apartamento conocido por sus detalles de aspecto surrealista: por la hierba y los árboles de la terraza, por los cuadros colgados en el exterior y por la falsa chimenea, posteriormente rematada con un espejo (no importa aquí si por Dalí o por el propio De Beistegui) que desmaterializa el borde superior del antepecho. [8]

La chimenea del salón de Little Thakaham, a diferencia de la incrustada por Le Corbusier en el antepecho, está en el sitio que le corresponde por su naturaleza, es decir, en un espacio interior. Pero el balcón que se abre sobre ella le concede igualmente un carácter de objeto inútil y paradójico. La chimenea de la terraza parisina desempeña un papel análogo al del balcón de Little Thakeham. Ambos se abren hacia donde no deben: la chimenea francesa hacia un espacio exterior y el balcón hacia un espacio interior. Mientras la chimenea concede a la terraza cierto carácter de espacio interior, el balcón concede al salón un carácter de espacio exterior, y en el caso de encender ambas chimeneas, la de Lutyens bajo el balcón y la de Le Corbusier en la terraza, el humo virtualmente escaparía.

Lutyens y Le Corbusier pueden ser comparados en razón de las ricas secuencias espaciales que proponen en sus residencias. La escalera de Little Thakeham, por ejemplo, obliga a realizar una emocionante promenade architeturale. Pero cabe también compararlos atendiendo a los montajes que ambos proponen. Según Alan Colqhuoun, Le Corbusier pretendía evocar la idea a
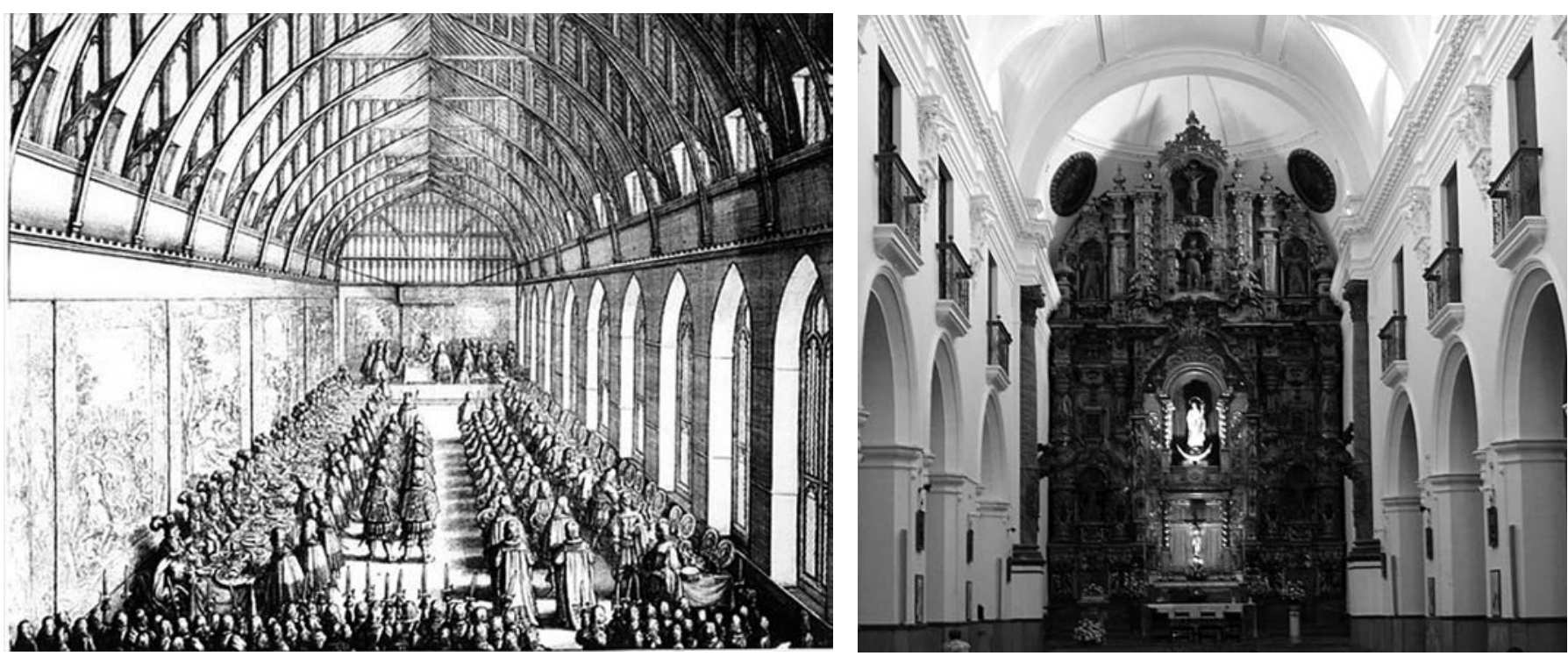
21 Muthesius, Hermann; The English House, BSP Professional Books, Oxford, 1979 (1908), pág 90. (Tit. or. Das Englische Haus, 1904).

22 Piaget, Jean; El nacimiento de la inteligencia en el niño, Crítica, Barcelona, 2000 (original 1936).

23 Wallon, Henri; Del acto al pensamiento.Ensayo de psicología comparada, Psique, Buenos Aires, 1987 (original 1942).

24 Benjamin, Walter; Sobre la facultad mimética, Ensayos escogidos, Ed. Sur, Buenos Aires, 1967 (original 1929). Benjamin, Walter; El surrealismo. La última instantánea de la inteligencia europea, Taurus Ed., Madrid, 1980 (original 1929).

25 Bozal, Valeriano; Mímesis: las imágenes y las cosas, Visor, Madrid, 1987.

${ }^{26}$ Colquhoun, Alan; Modernidad y tradición Clásica, Jucar Universidad, Madrid, 1991, pág 126.

${ }^{27}$ Rowe, Colin; Ciudad Collage, Gustavo Gili, Barcelona, 1981, pág 183.

${ }^{28}$ Los mejores arquitectos del siglo XVIII recurrieron igualmente a la yuxtaposición y el contraste.

Borromini, según Tafuri, al igual que los arquitectos del Quinientos inglés, utilizó las formas de un modo antidogmático: "También para él, como para estos últimos, la libertad de la cita o de la referencia adquiere un valor semántico determinado. Lo que es distinto es el papel que atribuimos a dichas

citas y referencias". Tafuri, Manfredo. Op. Cit., págs 45-46.

29 Ibid., pág 135. través de la imagen: "su guardarropa mental está lleno de objetos listos para ser utilizados en un bricolaje, objetos que han quedado impresos en su memoria en un momento de epifanía". 26

En algunos edificios de Le Corbusier, confirma Colin Rowe, "los objetos y episodios son importaciones entrometidas que, aunque conservan las matizaciones de su fuente y origen, consiguen también un impacto nuevo a partir de su contexto cambiado". ${ }^{27}$ Observaciones que valen también para Lutyens y que pueden servir para explicar el extraño conjunto formado por la chimenea y el balcón de Little Thakeham.

Lutyens, al igual que Le Corbusier, recurrió al montaje para renovar los significados asociados a las formas y usos tradicionales. Nada nuevo en la historia de la arquitectura: ¿no son las cariátides un montaje -mujeres que hacen las veces de columnas- y no es el Erecteión un edificio compuesto por fragmentos? ${ }^{28}$ Los montajes propuestos por Lutyens y Le Corbusier son sin duda diferentes. Sería ingenuo sostener alguna relación inmediata entre ellos. Pero cabe compararlos en razón de los efectos que producen y de lo que tienen de experimental, entendiendo que esta actitud experimentalista, a diferencia de la vanguardista, afirmativa, absolutista y totalitaria, según Tafuri, "tiende a desmontar, recomponer, contradecir y llevar a la exasperación sintaxis y lenguajes aceptados como tales". ${ }^{29}$

El experimentalismo que comparten Lutyens y Le Corbusier, en definitiva, permite proyectar las innovaciones hacia lo desconocido, pero sin dejar de sostenerse sobre un fundamento firmemente arraigado. Las analogías mencionadas ponen de manifiesto que el juego de Lutyens es el universal juego de la mímesis y el montaje. No el juego de las yuxtaposiciones extravagantes o exóticas, sino el de los contrastes significativos. Un juego que no entiende las formas ajenas como problema, sino que las pone al servicio de la recreación.

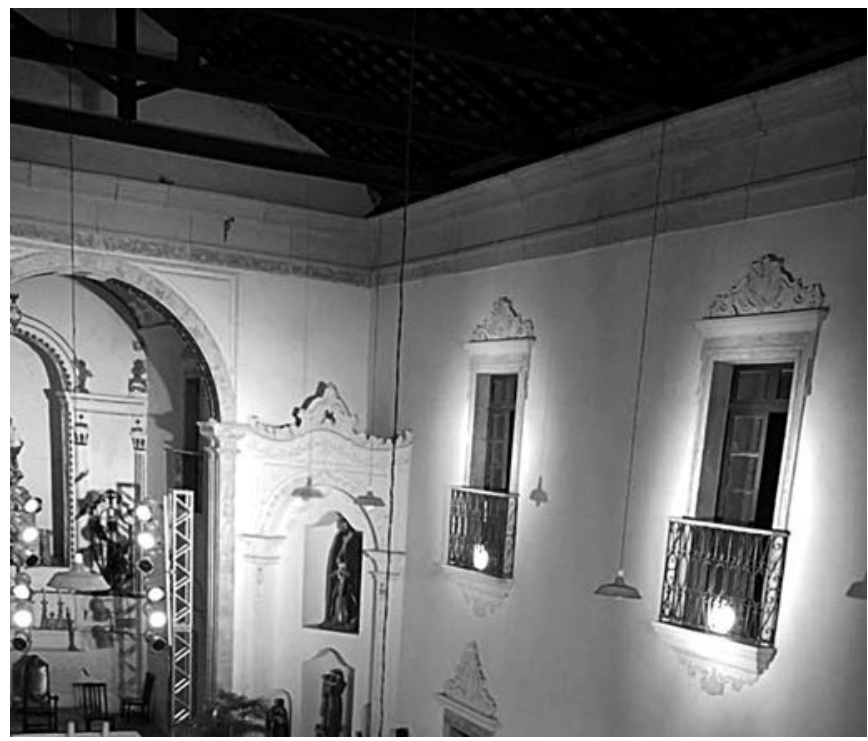

* Manuel de Prada es arquitecto y profesor de Composición Arquitectónica y del Máster en Análisis, Teoría e Historia de la Arquitectura en la ETSAM. Ha sido responsable de la asignatura Análisis de Formas, de varios seminarios sobre arte y de un taller de proyectos arquitectónicos en la Universidad SEK de Segovia. Ha publicado varios libros sobre arte y arquitectura.

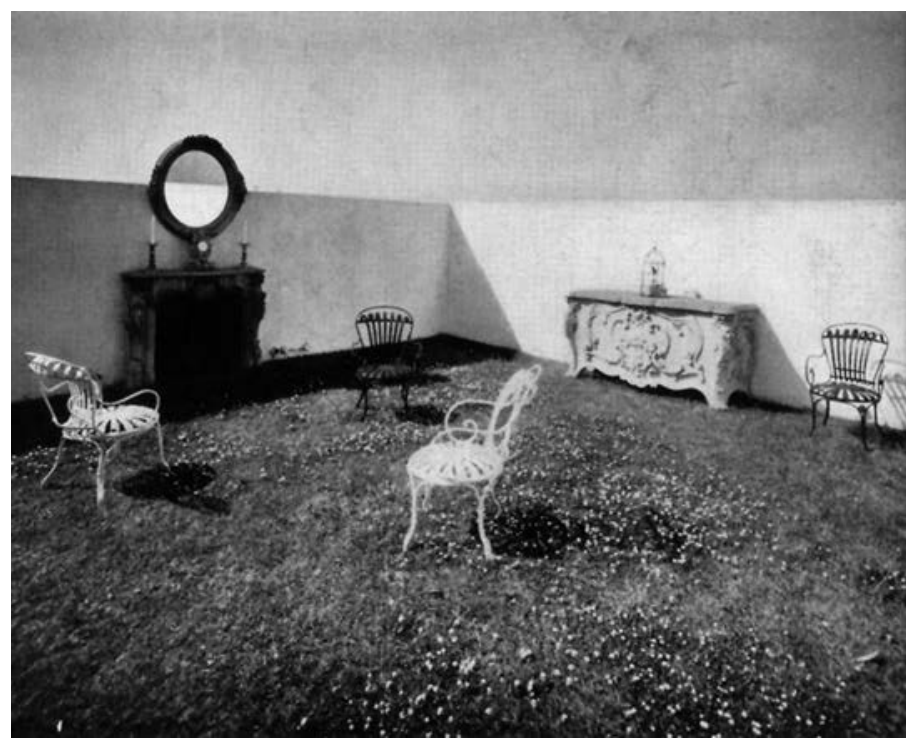

